indicates that the service is a vital one \& suggestions about improvements will help inform service development plans.

\section{P127 HOSPICE RESPITE: MOVING FORWARDS NOT BACKWARDS}

Lindsay Day, Amanda Gregory, Paul Read. St. Catherine's Hospice, Crawley, UK

\subsection{6/bmjspcare-2013-000591.149}

Anecdotal evidence suggested that respite provision at an independent hospice was dominated by patients with neurological or non cancer diagnoses and that a small number of patients had a disproportionately large amount of respite admissions compared to those with a cancer diagnosis. A service review was undertaken to investigate whether the provision of respite was equitable across all patient groups. A retrospective review of notes identified patients referred for a respite admission within a 12 month period. The individual patient files were scrutinised to obtain relevant data for analysis, including the level of specialist palliative care received prior to admission. Respite provision appeared to attract a fairly equal number of referrals across cancer and non-cancer groups, although the latter were more likely to access multiple episodes of respite. Of the non-cancer groups, those with a neurological condition represented the highest proportion of patients accessing respite. It is likely that these results are due to the longer term, unpredictable nature of non-cancer conditions resulting in increased carer burden and subsequent need for respite care. The care needs of non-cancer patients suggest that a specialist palliative care centre is not necessarily required for respite. It is recommended that: alternative models of respite care are explored for these patients such as nursing home or an increase in home-care packages; the hospice continues to support local nursing home providers in order to facilitate the provision of high quality respite care within our community; during a patient's first respite admission, an assessment is undertaken to determine the most suitable place for ongoing respite care; respite guidelines to be adjusted to reflect a specified number of admissions per year.

\section{P128 DOES RESPITE CARE ADDRESS THE NEEDS OF PALLIATIVE CARE SERVICE USERS AND CARERS?}

${ }^{1}$ Anna Wolkowski, ${ }^{2}$ Susan Carr. ${ }^{1}$ Dove House Hospice, Hull, UK, ${ }^{2}$ University of Northumbria, Newcastle

\subsection{6/bmjspcare-2013-000591.150}

Research aims To explore the perspectives and experience of respite care of married or bereaved palliative care service users and carers and to establish in what ways respite care addresses their needs. The research is located in a professional doctorate study.

Background There are clear indications that over the coming years, as more people live longer into old age and die as a consequence of chronic disease, an increasing amount of support for carers of patients with palliative care needs will be required. In UK policy and guidance, respite care is frequently mentioned as a key factor in supporting carers. However, little is known about respite care for people in this group and the study addresses this gap in knowledge.

Methods The approach was qualitative, the methodology was interpretive and the method used was constructivist Grounded
Theory. Data collection was carried out by unstructured informal interview with couples who had experienced hospice respite care. Social network circle activity was undertaken as part of theoretical sampling.

Results Respite care is valued by palliative care service users and carers although there are some fundamental tensions in service models which limit its potential. A theory of vulnerability and resilience was developed which accommodated issues of needs and acceptance, choice and risk, loss and gains.

Conclusions The articulation of respite care needs and the insights gained in this study have the potential to influence hospice practice and provide a platform for innovative service development and improvement which is sensitive to the needs and capacity of local communities.

Application to hospice practice A reframing of respite care as an empathic response within a new palliative care approach is proposed. Within this the centrality of the relationship is reinforced and the need for support over a potentially long and more uncertain trajectory is acknowledged.

\section{P129 EQUITABLE ALLOCATION IN NEEDS-LED CARE: DEVELOPING AN ASSESSMENT TOOL FOR RESPITE ALLOCATION IN A HOSPICE FOR YOUNG ADULTS}

Sophie Ebeling, Deborah Cowee. Helen and Douglas House, Oxford, United Kingdom

\subsection{6/bmjspcare-2013-000591.151}

Background The hospice provides support for young people with life-limiting illnesses, central to which is respite care. It is recognised that decisions about respite care provision are of fundamental importance to patients and their families. The referrals team invests time, clinical judgment and combined knowledge to assess each case and agree an allocation of respite care.

A project was undertaken to develop a tool for allocation of respite care. This tool would structure the allocation of respite according to a matrix, allowing the team to provide evidence of equitable allocations, allow direct comparisons between cases and potentially improve time efficiency.

Aims The aim was to develop and validate a simple scoring matrix which could be used to assess each patient's need for respite and ensure an appropriate allocation of nights.

Approach The tool was developed through a grounded theory approach, refining and developing the tool through testing until an accurate version was created.

Outcomes This project has successfully captured, and defined, the collective knowledge and experience of the referrals panel. This collaborative decision-making process, that has historically relied heavily on personal and professional knowledge, combined with a holistic understanding of the complex lives and needs of patients and their families, has been explored. These tacit aspects have been articulated, defined and quantified in the assessment tool produced.

Application This project represents a step forward, in response to current national agendas that call for hospices to demonstrate quality and equity ahead of GP Commissioning.

Adopting the tool will ensure that allocation continues to be a transparent and equitable process, which is able to be articulated and justified to patients, families and wider colleagues, allowing the organisation to demonstrate accountability and good governance. 